Research Article

\title{
Studies on Adsorption of Fluorescein Dye from Aqueous Solutions Using Wild Herbs
}

\author{
Ghadah M. Al-Senani $(D)$ and Nada S. Al-Kadhi \\ Department of Chemistry, College of Science, Princess Nourah Bint Abdulrahman University, Riyadh, Saudi Arabia \\ Correspondence should be addressed to Ghadah M. Al-Senani; gmalsnany@pnu.edu.sa
}

Received 31 July 2019; Revised 8 December 2019; Accepted 26 December 2019; Published 16 January 2020

Academic Editor: Danilo Corradini

Copyright ( $) 2020$ Ghadah M. Al-Senani and Nada S. Al-Kadhi. This is an open access article distributed under the Creative Commons Attribution License, which permits unrestricted use, distribution, and reproduction in any medium, provided the original work is properly cited.

\begin{abstract}
The adsorption of fluorescein dye (FD) on wild herb microparticles (Juniperus (JH) and Solenostemma argel (Del) Hayne (SH)) was studied to elucidate the changes in adsorption behavior with various parameters, such as initial concentration, adsorbent dosage, $\mathrm{pH}$, contact time, and temperature. It was determined that the adsorption percentage of JH for FD was as high as $85.5 \%$, which was higher than that of SH (71.9\%). The morphologies of JH and SH were analyzed using Fourier-transform infrared spectroscopy (FTIR), X-ray diffraction (XRD), and scanning electron microscopy (SEM) analyses. The JH and SH adsorbents contained different functional groups, which were involved in the binding of the FD molecules during adsorption. The XRD patterns of JH and SH confirmed the presence of a combination of amorphous and crystalline phases in their structures. The SEM images of the surface of JH revealed the presence of deep pores ranging in size from 1.9 to $3.5 \mu \mathrm{m}$, while SH contained smaller pores ranging in size from 130 to $350 \mu \mathrm{m}$, which could help absorb large quantities of FD. The Freundlich model fitted the adsorption isotherms better than the Langmuir model. The values of the Freundlich equilibrium coefficient and separation factor ranged from 1 to 2 and from 0 to 1, respectively. The maximum adsorption capacities of $\mathrm{JH}$ and $\mathrm{SH}$ were determined to be 2.91 and $2.565 \mathrm{mg} / \mathrm{g}$, respectively. Four kinetic models were used to analyze the experimental data, and it was determined that the pseudo-second-order kinetic model best described the adsorption process, which involved chemical adsorption and the internal diffusion. Thermodynamic parameters, including the enthalpy, entropy, and Gibbs free energy, were calculated. These parameters indicated that the adsorption of FD on JH was spontaneous and endothermic and the adsorption of FD on SH was unspontaneous and exothermic.
\end{abstract}

\section{Introduction}

Industrial organic dyes are highly toxic, and therefore, the dyeing industry, which releases 100 tons of dyes in the environment annually, is responsible for the pollution of rivers and springs $[1,2]$. Most of the effluents from the textile industries are often loaded with a mixture of dyes, acids, bases, and soluble solids [3]. Once these pollutants are exposed to water, their removal via adsorption becomes difficult owing to their complex molecular structures, which can withstand various environmental conditions. Therefore, more studies on the treatment of aqueous solutions should be conducted to overcome this environmental problem, and methods that could be used to remove even small amounts of different types of synthetic dyes from wastewaters should be considered.
The textile industries often produce liquid wastes that are loaded with mixtures of dyes, acids, bases, and soluble solids [3], making adsorption difficult. Therefore, aqueous solutions treatment is one of the biggest problems we face today. Once the dyes are exposed to water, it is difficult to adsorption them, because they have a complex molecular structure, capable of tolerating various environmental conditions. Moreover, when the concentration of these dyes in water is low, the water is clear. Thus, the decolorization of aqueous solutions that contain different types of synthetic dyes is important.

The chemical structure of resorcinolphthalein or fluorescein dye (FD), which is one of the commercially available textile dyes, is shown in Figure 1.

The molecular formula of $\mathrm{FD}$, which is widely used as artificial coloring agent, is $\mathrm{C}_{20} \mathrm{H}_{12} \mathrm{O}_{5}$. Fluorescein dye can be 


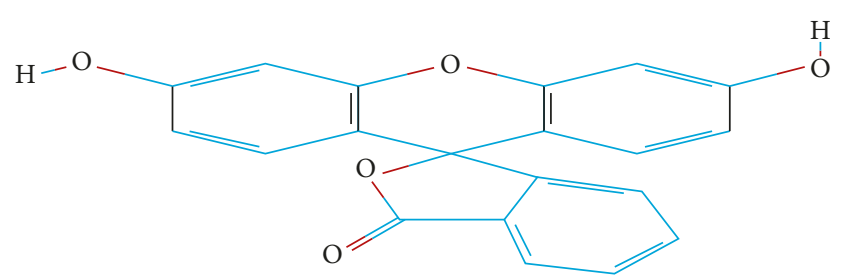

Figure 1: Chemical structure of the fluorescein $\left(\mathrm{C}_{20} \mathrm{H}_{12} \mathrm{O}_{5}\right)$ dye.

obtained by heating resorcinol and phthalic anhydride on a zinc catalyst; the obtained product is a crystalline dark red powder, and its melting point ranges from 314 to $316^{\circ} \mathrm{C}$. Resorcinolphthalein is also known as FD owing to its strong green fluorescein alkaline solutions even at low concentration. To date, FD has been used as dye for liquid coloring in analytical devices, in the cosmetics industries, and as aqueous detector.

While no specific method exists for the complete adsorption of dyes from aqueous solutions, some of the traditional methods for removing dyes from aqueous solutions involve biological treatment, coagulation, buoyancy, adsorption, oxidation, and excessive filtration [3], and the most important treatment of all these methods is adsorption.

Adsorption is the process where molecules from aqueous solutions adhere on the surface of the adsorbent surface via physical forces or chemical bonds. Depending on the nature of the adsorbents and the chemical structure of the dyes, adsorption occurs via electrostatic interactions or van der Waals forces.

Many natural materials, including coffee waste, have been used to adsorb various pollutants from aqueous solutions $[4,5]$. Large amounts of coffee beans are produced and used worldwide, and coffee waste has been used to adsorb hazardous particles from aquifers and gaseous mixtures or for the desalinization of water [6]. Coffee powder has been used as low-cost additive for the adsorption of a series of rhodamine dyes, such as rhodamine $\mathrm{B}$ and rhodamine $6 \mathrm{G}$, from aqueous solutions [7]. Aleurites moluccanus seeds have been used for the adsorption of methylene blue dye and rhodamine B from aqueous solutions [8]. Moreover oat hulls [9], date palm fiber [10], and wood apple shells [11] have been used for the adsorption of malachite green from aqueous solutions; water hyacinth [12], date palm fiber [13], and Calligonum comosum leaf powder [14] have been used for the adsorption of crystal violet dye from aqueous solution; date palm leaf [15] has been used for the adsorption of Congo red dye from aqueous solution; teak leaf powder [16] has been studied for the adsorption of eosin yellow; and kenaf core fiber has been used for the adsorption of reactive anionic [17] and acidic dyes [18].

The aim of this study was to analyze the kinetics and thermodynamics of the adsorption of FD from aqueous solution using wild herb microparticles.

\section{Materials and Methods}

2.1. Materials. We purchased FD from Sigma-Aldrich (St. Louis, MO, USA) and used distilled water to prepare FD solution.
Juniperus (JH; Figure 2), which is an evergreen trees with seedless fruit that typically grows in cold climates, is abundant in southern Saudi Arabia. The branches of $\mathrm{JH}$ secrete a dark colored substance that presents medical uses [19].

Solenostemma argel (Del) Hayne (SH; Figure 2), which is a simple herbaceous plant, blooms in the summer and can be found in many mountainous and desert regions of the Arabian Peninsula and North Africa [20]. Its small white flowers are grouped in tentacles and its fruit is smooth, velvety, fossilized, and dark red.

2.2. Preparation of Adsorbents. The $\mathrm{JH}$ and $\mathrm{SH}$ adsorbents used in this study were purchased from perfumer. The herbs were first dried at $50^{\circ} \mathrm{C}$ for $30 \mathrm{~min}$, and then they were cut into small pieces and ground to powder using a laboratory planetary ball mill (DECO-PBM-V-0.4L). The powders were sieved into particles less than $50 \mu \mathrm{m}$ in size using an Octagon D200 digital sieve shaker and were stored in glass bottles for further use without any pretreatment.

2.3. Preparation of FD Solution. The FD stock solution $(1000 \mathrm{mg} / \mathrm{L})$ was prepared using double distilled water. All solutions used in the experiments were prepared by diluting the stock solution to predetermined concentrations.

2.4. Methods. The adsorption experiments were performed in flasks that contained $100 \mathrm{~mL}$ FD solution of predetermined concentration and different amounts of adsorbent herbs. The adsorption equilibrium was investigated for different dye concentrations that ranged between 2 and $10 \mathrm{mg} / \mathrm{L}$. In addition, kinetics experiments were conducted using dye with the concentration of $10 \mathrm{mg} / \mathrm{L}$ and $0.5 \mathrm{~g}$ adsorbent at $25^{\circ} \mathrm{C}$. The mixtures were shaken at $120 \mathrm{rpm}$ for $16 \mathrm{~h}$ using a Rotaterm orbital and linear shaker.

The initial concentration of dye in this study was $10 \mathrm{mg} /$ L. The effect of the $\mathrm{pH}$ on the adsorption of FD was investigated, and the $\mathrm{pH}$ was adjusted in the range of 3-12 using either $1 \mathrm{M} \mathrm{NaOH}$ or $1 \mathrm{M} \mathrm{HCl}$. A pH meter was used to monitor the changes in $\mathrm{pH}$. In addition, the adsorbentadsorbate contact time was varied between 30 and $240 \mathrm{~min}$. The effect of the temperature on the adsorption process was studied in the range of 25 to $70^{\circ} \mathrm{C}$ for $3 \mathrm{~h}$; the amount of adsorbent and the initial dye concentration used for these experiments were $0.5 \mathrm{~g}$ and $10 \mathrm{mg} / \mathrm{L}$, respectively, and $10 \mathrm{mg} / \mathrm{L}$, respectively [21]. All mixtures were filtered using 42 micron Whatman filter paper, and the dye concentrations were determined using a UV/Vis spectrophotometer at the wavelength of $450 \mathrm{~nm}$.

The quantity of dye adsorbed at equilibrium $\left(q_{\mathrm{e}}(\mathrm{mg} / \mathrm{g})\right)$ was calculated using the following equation [21]:

$$
q_{\mathrm{e}}=\frac{\left(C_{0}-C_{\mathrm{e}}\right) V}{m},
$$

where $C_{0}$ and $C_{\mathrm{e}}(\mathrm{mg} / \mathrm{L})$ are the initial concentrations of dye and the equilibrium concentration of dye at equilibrium, 


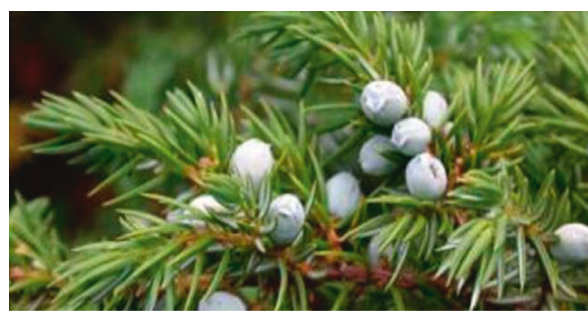

(a)

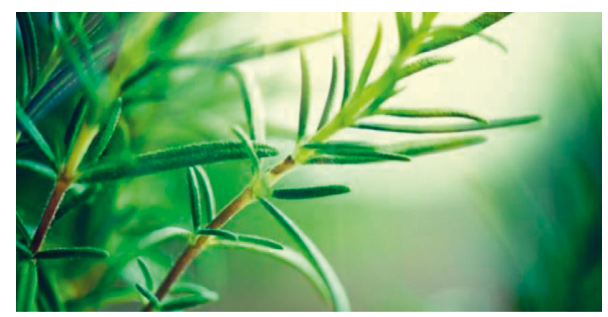

(b)

FIgURe 2: Juniperus (JH) and Solenostemma argel (Del) Hayne (SH).

respectively, $V(\mathrm{~L})$ is the volume of the solution, and $m(\mathrm{~g})$ is the mass of adsorbent.

The percentage of FD adsorbed from the solution (Ads $\mathrm{FD}$ (\%)) was calculated using the following equation [21]:

$$
\operatorname{Ads}_{\mathrm{FD}} \%=\frac{\left(C_{0}-C_{\mathrm{e}}\right)}{C_{0}} \times 100 .
$$

Four kinetic models were used to describe the behavior of adsorbent, and the Langmuir and Freundlich isotherm models were employed to study the adsorption data. The following thermodynamic parameters, enthalpy $\left(\Delta H^{\circ}\right)$, entropy $\left(\Delta S^{\circ}\right)$, and free energy $\left(\Delta G^{\circ}\right)$, were calculated, and the results were used to study and interpret the effect of temperature on the adsorption process.

The functional groups that participated in the adsorption processes were determined using Fourier-transform infrared (FTIR) spectroscopy and X-ray diffraction (XRD) analysis. Scanning electron microscopy (SEM) images of the adsorbent surfaces were obtained using a JSM-6380 LA SEM instrument with the high resolution of $3.0 \mathrm{~nm}$.

\section{Results and Discussion}

3.1. Characterization of Adsorbents. The FTIR spectra of the adsorbents were used to differentiate functional groups, such as $-\mathrm{OH}$ (alcohols and carboxylic acids), $-\mathrm{CH}-$ (alkanes), $-\mathrm{N}-\mathrm{H}$ (amines), and $\mathrm{C}=\mathrm{O}$ (carbonyl), present in the structure of $\mathrm{JH}$ and $\mathrm{SH}$ (Figure 3), which could form bond with FD during adsorption and therefore could play important roles in adsorption of FD $[22,23]$. The absorption peaks identified in the FTIR spectra of $\mathrm{JH}$ and $\mathrm{SH}$ are summarized in Table 1.

A broad hump and a sharp diffraction peak were observed in the XRD patterns of JH and SH (Figure 4), which indicated that the adsorbents consisted of combinations of amorphous and crystalline structures.

The SEM images of the surface of $\mathrm{JH}$ and $\mathrm{SH}$ adsorbents are presented in Figures 5(a) and 5(b); JH contained deep pores ranging in size from 1.9 to $3.5 \mu \mathrm{m}$ and the SH contained smaller pores ranging in size from 130 to $350 \mu \mathrm{m}$. This explains that the presence of these deep pores with the size of the micrometer greatly aids in adsorption of large quantities of FD molecules on the surface of adsorbents.

3.2. Effect of Initial FD Concentration on Adsorption. In this study, the initial concentration of FD, which varied from 2 to
$10 \mathrm{mg} / \mathrm{L}$, affected the percentage of FD adsorbed. When the initial FD concentration increased, the percentage of adsorbed FD decreased (Figure 6). The lowest percentage of adsorbed FD was associated with the highest initial concentration of FD. At high FD concentrations, the competitive dispersion of FD at the pores available on the adsorbent surface increased [17]; therefore, the pores were closed and the FD molecules were prevented from migrating into the deep pores of the absorbent. Consequently, adsorption occurred only at the surface of the adsorbent $[24,25]$.

3.3. Effect of Adsorbent Dose on Adsorption. The effect of the adsorbent dose on the adsorption of $\mathrm{FD}$ on $\mathrm{JH}$ and $\mathrm{SH}$ was studied. The percentage of adsorbed FD increased as the adsorbent doses increased (Figure 7). This was attributed to the increased availability of exchange sites or the increase in the surface area that featured large number of adsorption sites [26].

3.4. Effect of Contact Time on Adsorption. The adsorption equilibria were analyzed for 30 to $240 \mathrm{~min}$. The FD adsorption rates of both adsorbents ( $\mathrm{JH}$ and $\mathrm{SH}$ ) increased in time (Figure 8). The percentage of adsorbed FD increased rapidly during the first $120 \mathrm{~min}$ of adsorbent-adsorbate contact, and then the process slowed down for both adsorbents. This occurred because the number of active adsorption sites decreased in time $[9,24]$.

3.5. Effect of $p H$ on Adsorption. Adsorption experiments were carried out at various $\mathrm{pH}$ levels between 3 and 12 to evaluate the effect of the $\mathrm{pH}$ of the FD solution on the percentage of FD adsorbed on both $\mathrm{JH}$ and $\mathrm{SH}$. The percentage of adsorbed FD decreased slightly as the $\mathrm{pH}$ was increased from 3 to 5 ; as the $\mathrm{pH}$ was further increased and exceeded 7 , the percentage of adsorbed FD increased for both adsorbents (Figure 9). At $\mathrm{pH}$ values exceeding 8, the percentage of adsorbed FD decreased as the $\mathrm{pH}$ was further increased.

The $\mathrm{pH}$ of the aqueous solution is an important parameter, because it affects the ionization of dye molecules and surface charge of adsorbents [7].

The percentage of adsorbed FD decreased as the $\mathrm{pH}$ was increased from 6 to 12 . That could be attributed to the adsorption of $\mathrm{OH}^{-}$ions on the surface of the adsorbents causing the surface to become negatively charged. Moreover, 


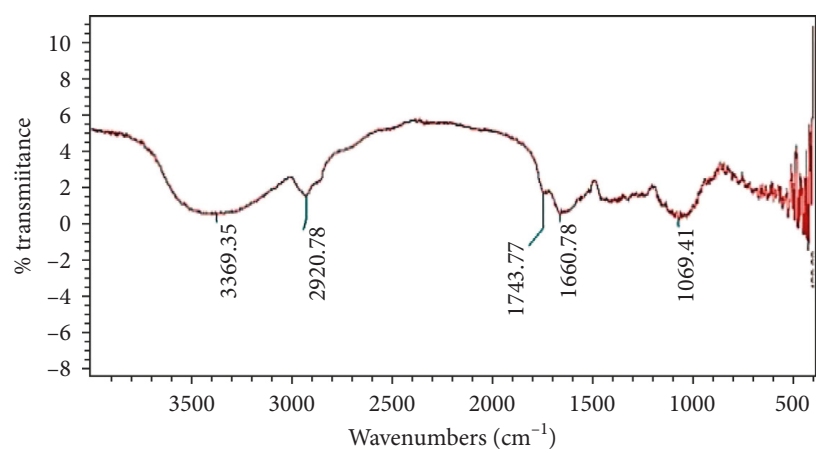

(a)

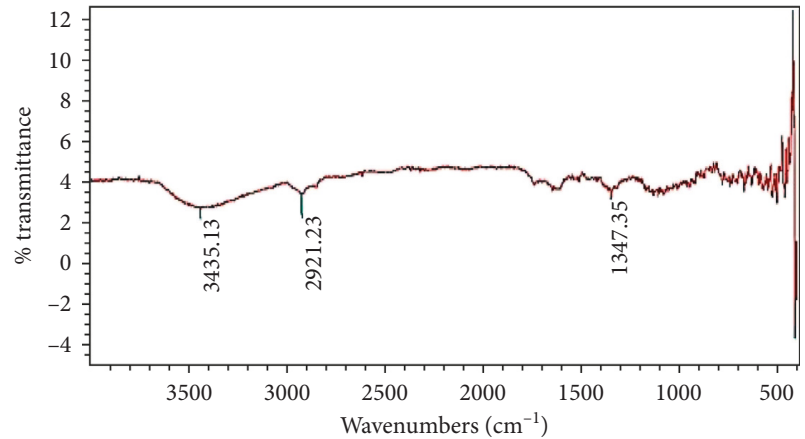

(b)

FIGURE 3: FTIR analysis of the functional groups in (a) JH and (b) $\mathrm{SH}$.

TABLE 1: FT-IR peaks of the functional groups in $\mathrm{JH}$ and $\mathrm{SH}$.

\begin{tabular}{lcc}
\hline Adsorbent & Peaks $\left(\mathrm{cm}^{-1}\right)$ & Functional groups \\
\hline JH & $3392.81-3423.84,2913.05-2925.31,1625.25-1728.04$, & $-\mathrm{OH},-\mathrm{COOH},-\mathrm{N}-\mathrm{H},-\mathrm{C}-\mathrm{H}, \mathrm{C}=\mathrm{O}$ \\
SH & $1078.93-1016.49$ & \\
\hline
\end{tabular}

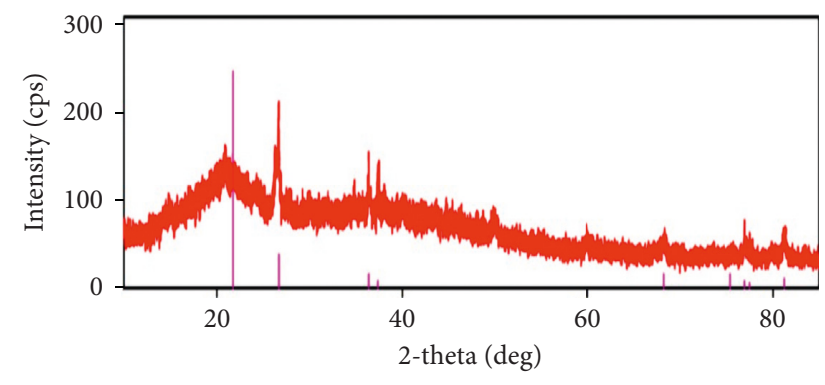

(a)

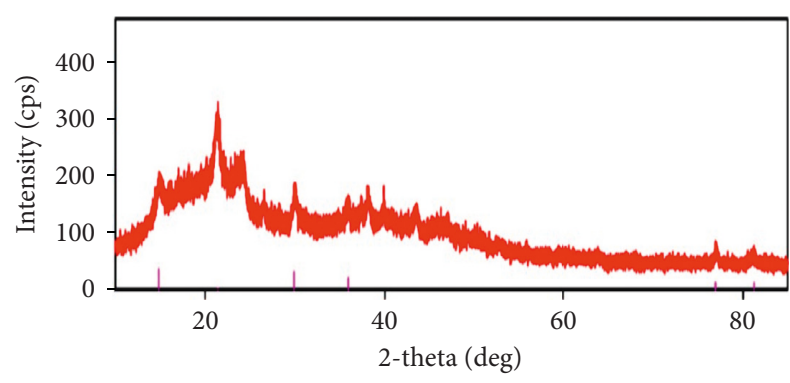

(b)

FIGURE 4: XRD pattern of (a) JH and (b) SH.
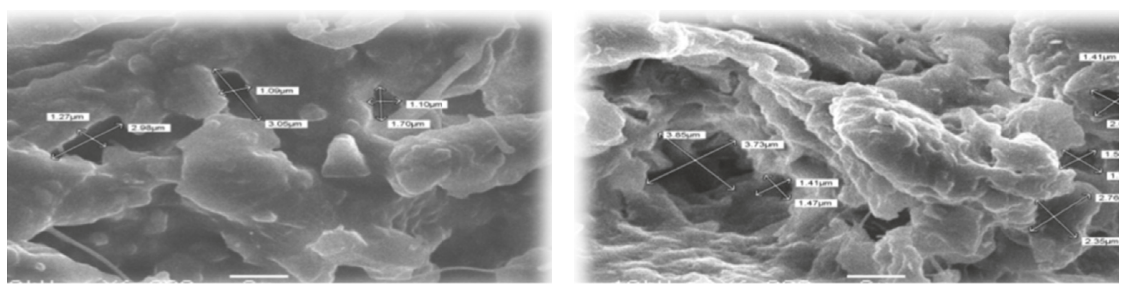

(a)
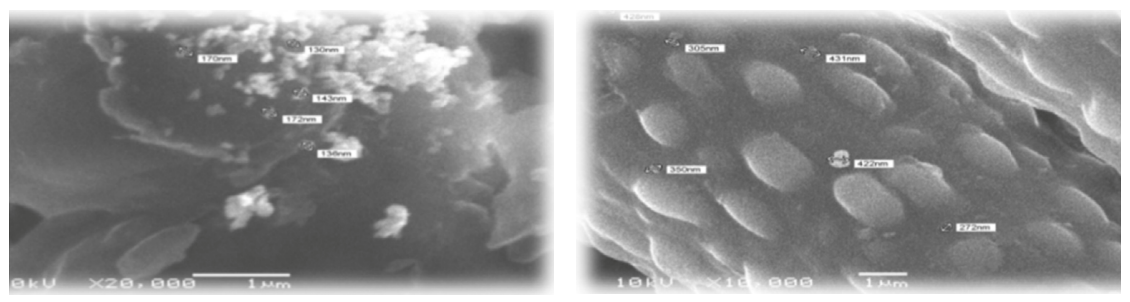

(b)

FIgURE 5: SEM photograph for surface of JH and SH before (a) and after (b) adsorption processes. 


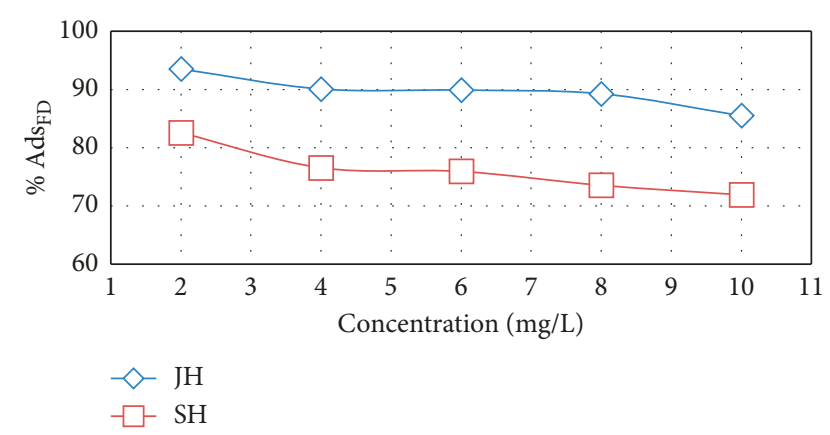

FIGURE 6: Effect of initial concentration on quantity of FD adsorbed by $\mathrm{JH}$ and $\mathrm{SH}$ (adsorbent dosage, $0.5 \mathrm{~g}$; solution volume, $100 \mathrm{~mL}$; contact time, $16 \mathrm{~h}$; and temperature, $25^{\circ} \mathrm{C}$ ).

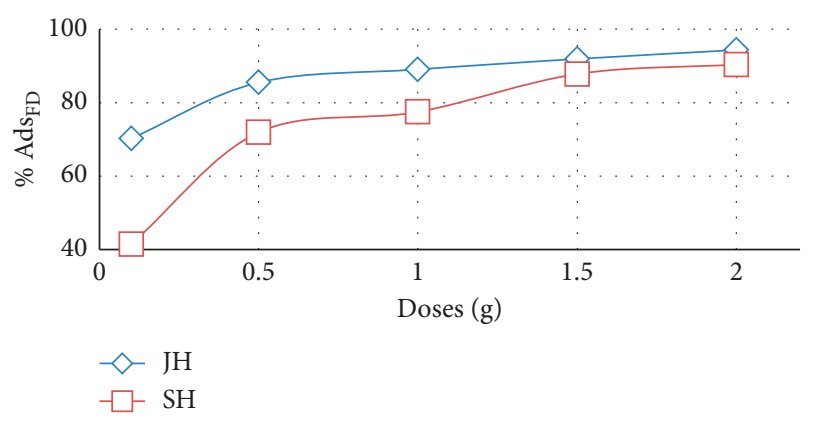

FIGURE 7: Effect of adsorbent dose on quantity of FD adsorbed by $\mathrm{JH}$ and $\mathrm{SH}$ (concentration of FD, $10 \mathrm{mg} / \mathrm{l}$; solution volume, $100 \mathrm{~mL}$; and temperature, $25^{\circ} \mathrm{C}$ ).

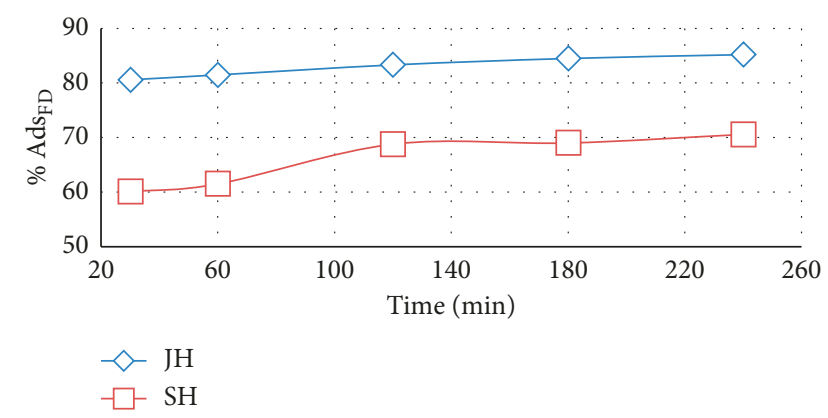

FIGURE 8: Effect of contact time on quantity of FD adsorbed by JH and $\mathrm{SH}$ (adsorbent dosage, $0.5 \mathrm{~g}$; concentration of FD, $10 \mathrm{mg} / \mathrm{l}$; solution volume, $100 \mathrm{~mL}$; and temperature, $25^{\circ} \mathrm{C}$ ).

the functional groups of the adsorbents, such as the $-\mathrm{OH}$ and $\mathrm{C}=\mathrm{O}$ groups, could occur between these groups and the anionic FD molecules. Consequently, the percentage of adsorbed FD decreased when the $\mathrm{pH}$ increased from 6 to 12 [27].

3.6. Effect of High Temperature on Adsorption. Our experimental results indicated that when the temperature increased from 25 to $70^{\circ} \mathrm{C}$, the percentage of $\mathrm{FD}$ adsorbed on $\mathrm{JH}$ increased and the percentage of $\mathrm{FD}$ adsorbed on $\mathrm{SH}$ decreased. All experiments were performed at $\mathrm{pH}$ of 8.5 and initial FD concentration of $10 \mathrm{mg} / \mathrm{L}$ (Figure 10).

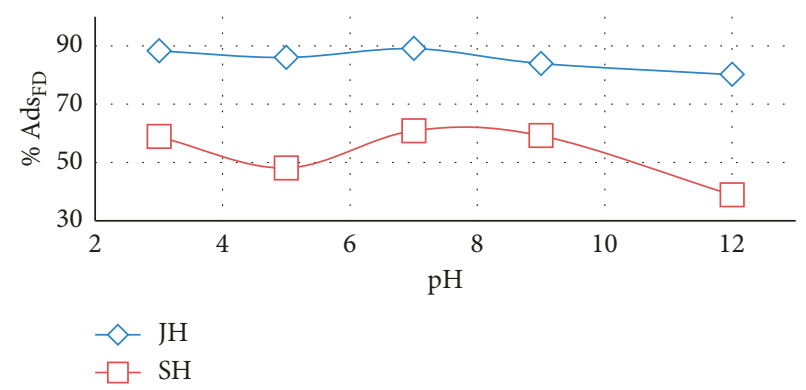

Figure 9: Effect of $\mathrm{pH}$ on quantity of FD adsorbed by JH and $\mathrm{SH}$ (adsorbent dosage, $0.5 \mathrm{~g}$; concentration of FD, $10 \mathrm{mg} / \mathrm{l}$; solution volume, $100 \mathrm{~mL}$; contact time, $16 \mathrm{~h}$; and temperature, $25^{\circ} \mathrm{C}$ ).

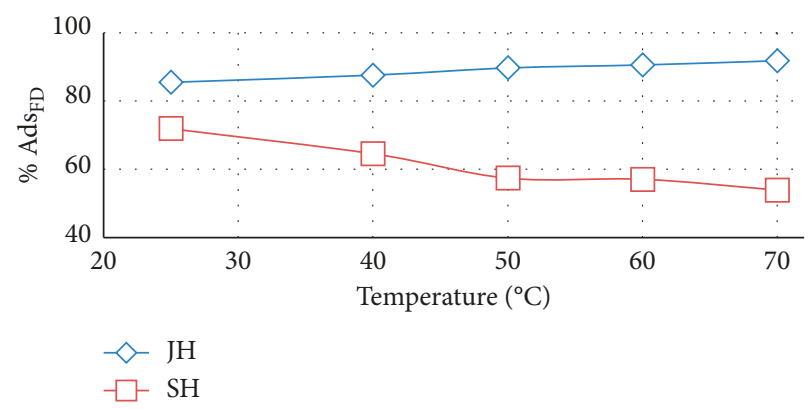

FIGURE 10: Effect of temperature on quantity of FD adsorbed by JH and $\mathrm{SH}$ (adsorbent dosage, $0.5 \mathrm{~g}$; concentration of $\mathrm{FD}, 10 \mathrm{mg} / \mathrm{l}$; solution volume, $100 \mathrm{~mL}$; and contact time, $4 \mathrm{~h}$.

The increase in the percentage of FD adsorbed on $\mathrm{JH}$ with the temperature could indicate that FD reacted with the functional groups on the surface of JH [28].

Conversely, the bonds between the FD molecules and functional groups on the surface of $\mathrm{SH}$ were physical bonds and could be easily broken at high temperature [29-32].

\section{Adsorption Isotherm Models}

To elucidate the adsorption mechanism of FD from aqueous solutions using $\mathrm{JH}$ and $\mathrm{SH}$ as adsorbents, we used the Langmuir and Freundlich adsorption isotherm models.

The Langmuir adsorption isotherm model assumes that adsorption occurs on the surface of the adsorbent and is a monolayer process [33] and could be described as follows [29]:

$$
\frac{C_{\mathrm{e}}}{q_{\mathrm{e}}}=\frac{1}{K_{\mathrm{L}} q_{\mathrm{m}}}+\frac{C_{\mathrm{e}}}{q_{\mathrm{m}}},
$$

where $C_{\mathrm{e}}(\mathrm{mg} / \mathrm{L})$ is the concentration of adsorbate at equilibrium, $q_{\mathrm{e}}$ is the adsorption capacity at equilibrium, $q_{\mathrm{m}}$ is the maximum adsorption capacity of the adsorbate, and $K_{\mathrm{L}}$ is the adsorption equilibrium constant. The relationships between $C_{\mathrm{e}} / q_{\mathrm{e}}$ and $C_{\mathrm{e}}$ for the adsorption of $\mathrm{FD}$ on JH and $\mathrm{SH}$ were linear (Figure 11), and the slopes of the plots and correlation coefficients $\left(R^{2}\right)$ are listed in Table 2. Experimental results revealed that the Langmuir adsorption isotherm is good with the JH adsorbent and did not fit with the $\mathrm{SH}$ adsorbent; moreover, the maximum theoretical 

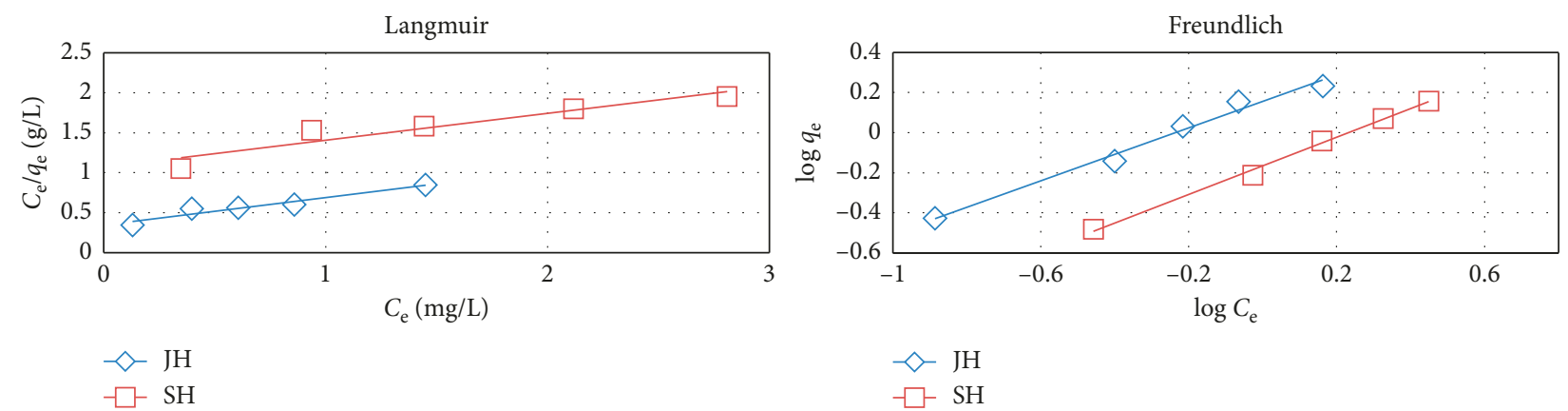

FIGURE 11: Langmuir and Freundlich isotherms plots for the FD adsorption by JH and SH (adsorbent dosage, $0.5 \mathrm{~g}$; concentration of FD, $10 \mathrm{mg} / \mathrm{l}$; solution volume, $100 \mathrm{~mL}$; contact time, $16 \mathrm{~h}$; and temperature, $25^{\circ} \mathrm{C}$ ).

TABLE 2: Adsorption isotherm parameters.

\begin{tabular}{lccc}
\hline Adsorption isotherm & \multirow{2}{*}{ Parameter } & \multicolumn{2}{c}{ Adsorbent } \\
models & & $\mathrm{JH}$ & $\mathrm{SH}$ \\
\hline & $q_{\mathrm{m}}(\mathrm{mg} / \mathrm{g})$ & 2.912 & 2.565 \\
Langmuir model & $K_{\mathrm{L}}(\mathrm{L} / \mathrm{mg})$ & 0.993 & 0.376 \\
& $R_{\mathrm{L}}$ & 0.091 & 0.210 \\
& $R^{2}$ & 0.936 & 0.867 \\
\hline \multirow{3}{*}{ Freundlich model } & $K_{\mathrm{F}}\left(\mathrm{mg}^{(1-1 / n)} \mathrm{g}^{-1} \mathrm{~L}^{1 / n}\right)$ & 1.433 & 0.669 \\
& $n$ & 1.514 & 1.470 \\
& $R^{2}$ & 0.985 & 0.987 \\
\hline
\end{tabular}

adsorption capacities of the adsorbents are greater than the experimental ones [8].

A dimensionless physicochemical constant was applied as separation factor $\left(R_{\mathrm{L}}\right)$, which indicated the favorable nature of the adsorption process, and was calculated as follows [30]:

$$
R_{\mathrm{L}}=\frac{1}{1+K_{\mathrm{L}} C_{0}} .
$$

The separation factor $R_{L}$ for the adsorption of FD on JH ranged from 0 to 1 , which indicated the adsorption was favorable (Table 2). Typically, $R_{\mathrm{L}}$ indicates whether the isotherm type is irreversible $\left(R_{\mathrm{L}}=0\right)$, favorable $\left(0<R_{\mathrm{L}}<1\right)$, linear $\left(R_{\mathrm{L}}=1\right)$, or unfavorable $\left(R_{\mathrm{L}}>1\right)$ [30].

The Freundlich adsorption isotherm model is an experimental equation and another form of Langmuir, which can be applied to the multilayer adsorption process [33] and could be described as follows [30]:

$$
\log q_{\mathrm{e}}=\log K_{\mathrm{F}}+\frac{1}{n} \log C_{\mathrm{e}}
$$

where $n$ is the Freundlich equilibrium coefficient. The plot of the relationship between $\log q_{\mathrm{e}}$ and $\log C_{\mathrm{e}}$ is presented in Figure 11, and the slope and $R^{2}$ values are listed in Table 2 . The $R^{2}$ values indicated that the Freundlich model fitted the experimental results better than the Langmuir one. The magnitude $n$ can be used to assess the suitability of the adsorption process. When $n$ ranged from 1 to 2 , the adsorption of FD on $\mathrm{JH}$ and $\mathrm{SH}$ was somewhat difficult [30].

The obtained results revealed that the adsorption of FD on the surface of $\mathrm{JH}$ and $\mathrm{SH}$ was a multilayer process.

\section{Adsorption Kinetic Models}

The pseudo-first-order, pseudo-second-order, intraparticle diffusion, and liquid film diffusion kinetic models were used to elucidate the adsorption mechanism of FD on $\mathrm{JH}$ and $\mathrm{SH}$ and to determine the rate dominant step of the adsorption process.

The pseudo-first-order model (PFO) could be described as follows [28]:

$$
\log \left(q_{\mathrm{e}}-q_{t}\right)=\log q_{\mathrm{e}}-\frac{K_{1} t}{2.303}
$$

where $q_{\mathrm{e}}$ and $q_{t}$ represent the quantity of FD adsorbed at equilibrium and at the time, $t$, respectively, and $K_{1}$ is the rate constant of the pseudo-first-order reaction.

The pseudo-second-order model (PSO) could described as follows [28]:

$$
\frac{t}{q_{t}}=\frac{1}{K_{2} q_{\mathrm{e}}^{2}}+\frac{t}{q_{\mathrm{e}}}
$$

where $K_{2}$ is rate constant of the pseudo-second-order reaction.

The intraparticle diffusion (IPD) coefficient $K_{\text {ipd }}$ could be calculated using the following equation [28]:

$$
q_{t}=K_{\mathrm{ipd}} t^{1 / 2}-C
$$

where $C$ is a constant that provides information on the thickness of the boundary layer.

The liquid film diffusion model (LFD) could described as follows [28]:

$$
-\ln (1-F)=K_{\mathrm{lfd}} t-C,
$$

where $F=q_{\mathrm{t}} / q_{\mathrm{e}}, K_{\mathrm{lfd}}$ is the rate constant of the liquid film diffusion reaction, $t$ is the time, and $C$ is a constant related to the boundary layer.

The linear plots of the four kinetic models for the adsorption of FD on $\mathrm{JH}$ and $\mathrm{SH}$ are presented in Figure 12. The parameters, constants, and $R^{2}$ values for the four kinetic models are listed in Table 3. The experimental $q_{\mathrm{e}}$ values of FD adsorbed did not agree with the calculated ones, and therefore the pseudo-first-order model did not fit well for the experimental data $[12,22]$. However, the pseudo-secondorder model fits well the kinetic data [28]. Furthermore, the results also revealed that the adsorption process involved the 

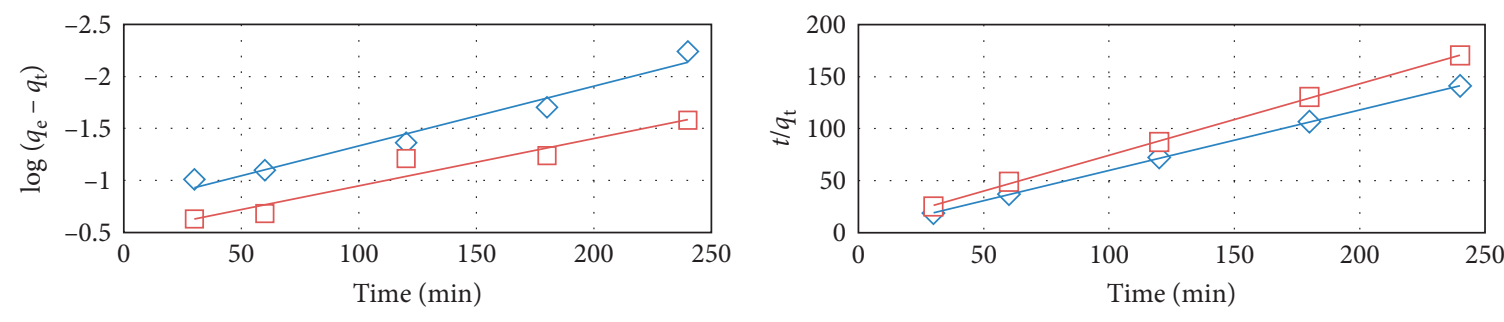

$\diamond \mathrm{JH}$

$\diamond \mathrm{JH}$

$\square \mathrm{SH}$

$\square \mathrm{SH}$

(a)

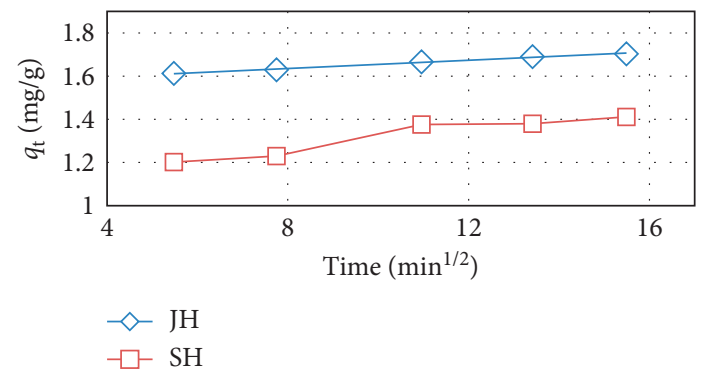

(c)

(d)

Figure 12: Plot of adsorption kinetic model ((a) PFO, (b) PSO, (c) IPD, and (d) LFD) for the FD adsorption by JH and SH (adsorbent dosage, $0.5 \mathrm{~g}$; concentration of $\mathrm{FD}, 10 \mathrm{mg} / \mathrm{l}$; solution volume, $100 \mathrm{~mL}$; and temperature, $25^{\circ} \mathrm{C}$ ).

TABle 3: Parameters of adsorption kinetic models.

\begin{tabular}{|c|c|c|}
\hline \multirow{2}{*}{ Kinetic models } & \multicolumn{2}{|c|}{ Adsorbent } \\
\hline & $\mathrm{JH}$ & $\mathrm{SH}$ \\
\hline$q_{\mathrm{e}, \exp }, \mathrm{mg} \mathrm{g}^{-1}$ & 1.710 & 1.438 \\
\hline \multicolumn{3}{|l|}{ Pseudo-first-order } \\
\hline$q_{\mathrm{e}, \mathrm{cal}}, \mathrm{mg} \mathrm{g}^{-1}$ & 0.174 & 0.273 \\
\hline$k_{1}, \mathrm{~g} / \mathrm{mg} \min$ & 0.013 & 0.008 \\
\hline$R^{2}$ & 0.969 & 0.853 \\
\hline \multicolumn{3}{|l|}{ Pseudo-second-order } \\
\hline$q_{\mathrm{e}, \mathrm{cal}}, \mathrm{mg} \mathrm{g}^{-1}$ & 1.720 & 1.436 \\
\hline$k_{2}, \mathrm{~g} / \mathrm{mg} \cdot \mathrm{min}$ & 0.197 & 0.097 \\
\hline$h, \mathrm{mgg}^{-1} \cdot \min$ & 0.583 & 0.200 \\
\hline$t^{1 / 2}$ & 16.56 & 9.28 \\
\hline$R^{2}$ & 0.999 & 0.999 \\
\hline \multicolumn{3}{|l|}{ Intraparticle diffusion } \\
\hline \multicolumn{3}{|l|}{ Step 1} \\
\hline$k_{\text {ipd }}, \mathrm{mgg}^{-1} \cdot \min ^{1 / 2}$ & 0.010 & 0.033 \\
\hline$C, \mathrm{mgg}^{-1}$ & 1.555 & 1.006 \\
\hline$R^{2}$ & 0.990 & 0.927 \\
\hline \multicolumn{3}{|l|}{ Step 2} \\
\hline$k_{\text {ipd }}, \mathrm{mg} \mathrm{g}^{-1} \cdot \min ^{1 / 2}$ & 0.008 & 0.003 \\
\hline$C, \mathrm{mgg}^{-1}$ & 1.576 & 1.338 \\
\hline$R^{2}$ & 0.991 & 0.907 \\
\hline \multicolumn{3}{|l|}{ Liquid-film diffusion } \\
\hline$K_{\mathrm{lfd}}, 1 / \mathrm{min}$ & 0.013 & 0.008 \\
\hline$C, \mathrm{mgg}^{-1}$ & 2.283 & 1.661 \\
\hline$R^{2}$ & 0.969 & 0.853 \\
\hline
\end{tabular}

exchanging or sharing of electrons between FD and $\mathrm{JH}$ and $\mathrm{SH}$, and this was the rate dominant step of the adsorption [27]. Further, the parameters of the intraparticle diffusion and the liquid film diffusion model, indicating that they are some of the factors determining the rate in the FD adsorption process (Table 3 ). The process consists of two steps or more, the first step being full diffusion on the adsorbent surface, the second step being the gradual diffusion of the particles into the pores, and the third step, which is the final equilibrium step. Figure 12 shows that the linear plots of dye adsorption did not pass through the original, indicating that FD adsorbed on the $\mathrm{JH}$ and $\mathrm{SH}$ was controlled by intraparticle diffusion and more than one mechanism is involved in adsorption. These results also indicated that $\mathrm{JH}$ was a better adsorbent for FD than SH.

\section{Thermodynamics of Adsorption}

The thermodynamic parameters, $\Delta S^{\circ}, \Delta H^{\circ}$, and $\Delta G^{\circ}$, were calculated using the following equations [34]:

$$
\begin{aligned}
K_{\mathrm{eq}} & =\frac{q_{\mathrm{e}}}{C_{\mathrm{e}}} \\
\ln K_{\mathrm{eq}} & =\frac{\Delta S^{\circ}}{R}-\frac{\Delta H^{\circ}}{R T}, \\
\Delta G^{\circ} & =\Delta H^{\circ}-T \Delta S^{\circ},
\end{aligned}
$$

where $K_{\mathrm{eq}}$ is the equilibrium constant, $q_{\mathrm{e}}(\mathrm{mg} / \mathrm{g})$ is the quantity of FD adsorbed at equilibrium, $C_{\mathrm{e}}(\mathrm{mg} / \mathrm{L})$ is the concentration of FD in solution at equilibrium, $R$ is the universal gas constant $(8.314 \mathrm{~mol} / \mathrm{K})$, and $T(\mathrm{~K})$ is the $\mathrm{ab}$ solute temperature of the solution. The Van't Hoff plots of ln $K_{\text {eq }}$ vs. $1 / T$ are illustrated in Figure 13 , and $\Delta S^{\circ}, \Delta H^{\circ}$, and $\Delta G^{\circ}$ 


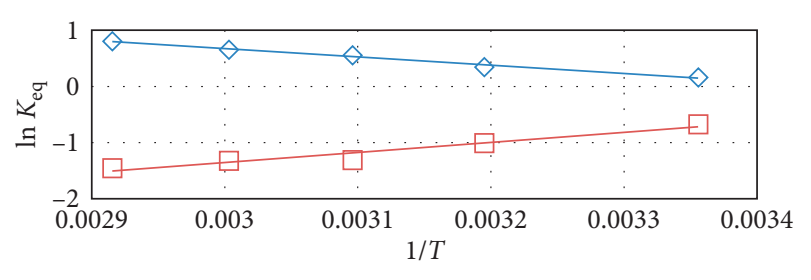

$\diamond \mathrm{JH}$

$\square \mathrm{SH}$

FIgURe 13: Van't Hoff plots for the FD adsorption by JH and SH (adsorbent dosage, $0.5 \mathrm{~g}$; concentration of FD, $10 \mathrm{mg} / \mathrm{l}$; solution volume, $100 \mathrm{~mL}$; and contact time, $4 \mathrm{~h}$.

TABLE 4: Thermodynamic parameters.

\begin{tabular}{lcc}
\hline \multirow{2}{*}{ Parameter } & \multicolumn{2}{c}{ Adsorbent } \\
\hline$\Delta H^{\circ}(\mathrm{kJ} / \mathrm{mol})$ & $\mathrm{JH}$ & $\mathrm{SH}$ \\
$\Delta S^{\circ}(\mathrm{J} / \mathrm{mol} \mathrm{K})$ & 12.27 & -14.87 \\
$\Delta G^{\circ}(\mathrm{kJ} / \mathrm{mol})$ at $298 \mathrm{~K}$ & 42.41 & -55.89 \\
$R^{2}$ & -0.37 & 15.17 \\
\hline
\end{tabular}

values are summarized in Table 4 . The $\Delta H^{\circ}$ and $\Delta S^{\circ}$ values were determined from the slopes and intercepts of the plots. The positive $\Delta H^{\circ}$ and $\Delta S^{\circ}$ values for the adsorption of FD on $\mathrm{JH}$ demonstrated the endothermic nature of the adsorption process. Conversely, the $\Delta H^{\circ}$ and $\Delta S^{\circ}$ values for the adsorption of $\mathrm{FD}$ on $\mathrm{SH}$ indicated that the process was exothermic and unspontaneous of the adsorption process $[27,34]$.

The negative $\Delta G^{\circ}$ values for the adsorption of FD on JH indicated that the adsorption was feasible and spontaneous. In addition, $\Delta G^{\circ}$ ranged from -20 to $0 \mathrm{~kJ} / \mathrm{mol}$ which indicated that the predominating adsorption mechanism was physical in nature $[30,35]$. The positive $\Delta G^{\circ}$ value for the adsorption of $\mathrm{FD}$ on $\mathrm{SH}$ indicated that the adsorption was unspontaneous.

\section{Conclusion}

In this study, the analysis of $\mathrm{JH}$ and $\mathrm{SH}$, which were used as adsorbents, revealed the presence of $-\mathrm{OH}$ (alcohols and carboxylic acids), - $\mathrm{CH}-$ (alkanes), $-\mathrm{N}-\mathrm{H}$ (amines), and $\mathrm{C}=\mathrm{O}$ (carbonyl) groups in their structures, and these groups participated in the adsorption of FD. The XRD patterns of JH and $\mathrm{SH}$ revealed that their structures were combinations of amorphous and crystalline phases. The SEM images of the surfaces of JH and SH revealed the presence of many deep micropores, which could adsorb large quantities of FD. The Langmuir and Freundlich isotherm models were used to describe the adsorption of FD on $\mathrm{JH}$ and $\mathrm{SH}$. The equilibrium data fitted well the Freundlich model. The percentage of $\mathrm{FD}$ adsorbed from aqueous solutions on $\mathrm{JH}$ was $85.5 \%$, which was higher than the percentage adsorbed on $\mathrm{SH}(71.9 \%)$. The $n$ and $R_{\mathrm{L}}$ values ranged from 1 to 2 and from 0 to 1 , respectively; moreover, $q_{\mathrm{m}}$ was determined to be 2.91 and $2.565 \mathrm{mg} / \mathrm{g}$ for $\mathrm{JH}$ and $\mathrm{SH}$, respectively. The kinetics of the adsorption FD on JH and $\mathrm{SH}$ were examined using the pseudo-first-order, pseudo-second-order, intraparticle diffusion, and liquid film diffusion models and was concluded that the adsorption followed the pseudo-second-order kinetic model, which involved chemical adsorption and the internal diffusion. The positive $\Delta H^{\circ}$ and $\Delta S^{\circ}$ values and negative $\Delta G^{\circ}$ value associated with the adsorption of FD on $\mathrm{JH}$ confirmed that the process was endothermic and spontaneous. Conversely, the negative $\Delta H^{\circ}$ and $\Delta S^{\circ}$ values and positive $\Delta G^{\circ}$ value associated with the adsorption of FD on $\mathrm{SH}$ suggested that the process was exothermic and unspontaneous. These results also indicated that $\mathrm{JH}$ was better than adsorbent for FD than SH. Further, the adsorption of dyes from aqueous solutions requires more studies.

\section{Data Availability}

The data used to support the findings of this study are included within the article.

\section{Conflicts of Interest}

The authors declare that there are no conflicts of interest regarding the publication of this article.

\section{Acknowledgments}

This research project was funded by the Deanship of Scientific Research, Princess Nourah Bint Abdulrahman University, through the Research Funding Program, Grant No. FRP-1440-5.

\section{References}

[1] B. Ramaraju, P. Manoj Kumar Reddy, and C. Subrahmanyam, "Low cost adsorbents from agricultural waste for removal of dyes," Environmental Progress \& Sustainable Energy, vol. 33, no. 1, pp. 38-46, 2014.

[2] S. S. Vieira, Z. M. Magriotis, N. A. V. Santos, M. D. G. Cardoso, and A. A. Saczk, "Macauba palm (Acrocomia aculeata) cake from biodiesel processing: an efficient and low cost substrate for the adsorption of dyes," Chemical Engineering Journal, vol. 183, pp. 152-161, 2012.

[3] N. Abdu-Salam and M. Buhari, "Adsorption of alizarin and fluorescein dyes on adsorbent prepared from mango seed," The Pacific Journal of Science and Technology, vol. 15, no. 1, 2014.

[4] A. Mittal, J. Mittal, A. Malviya, D. Kaur, and V. K. Gupta, "Adsorption of hazardous dye crystal violet from wastewater by waste materials," Journal of Colloid and Interface Science, vol. 343, no. 2, pp. 463-473, 2010.

[5] A. Mittal, J. Mittal, A. Malviya, and V. K. Gupta, "Removal and recovery of Chrysoidine $\mathrm{Y}$ from aqueous solutions by waste materials," Journal of Colloid and Interface Science, vol. 344, no. 2, pp. 497-507, 2010.

[6] M. G. Plaza, A. S. González, C. Pevida, J. J. Pis, and F. Rubiera, "Valorisation of spent coffee grounds as $\mathrm{CO} 2$ adsorbents for postcombustion capture applications," Applied Energy, vol. 99, pp. 272-279, 2012.

[7] K. Shen and M. A. Gondal, "Adsorption of hazardous Rhodamine dye from water by adsorption onto exhausted coffee 
ground," Journal of Saudi Chemical Society, vol. 21, pp. S120-S127, 2017.

[8] D. L. Postai, C. A. Demarchi, F. Zanatta, D. C. C. Melo, and C. A. Rodrigues, "Adsorption of rhodamine B and methylene blue dyes using waste of seeds of Aleurites Moluccana, a low cost adsorbent," Alexandria Engineering Journal, vol. 55, no. 2, pp. 1713-1723, 2016.

[9] S. Banerjee, G. C. Sharma, R. K. Gautam, M. C. Chattopadhyaya, S. N. Upadhyay, and Y. C. Sharma, "Removal of malachite green, a hazardous dye from aqueous solutions using Avena sativa (oat) hull as a potential adsorbent," Journal of Molecular Liquids, vol. 213, pp. 162-172, 2016.

[10] M. Alshabanat, R. Al-Mufarij, and G. Al-Senani, "Study on adsorption of malachite green by date palm fiber," Oriental Journal of Chemistry, vol. 32, no. 6, pp. 3139-3144, 2016.

[11] A. S. Sartape, A. M. Mandhare, V. V. Jadhav, P. D. Raut, M. A. Anuse, and S. S. Kolekar, "Removal of malachite green dye from aqueous solution with adsorption technique using Limonia acidissima (wood apple) shell as low cost adsorbent," Arabian Journal of Chemistry, vol. 10, pp. S3229-S3238, 2017.

[12] M. R. Kulkarni, T. Revanth, A. Acharya, and P. Bhat, "Removal of crystal violet dye from aqueous solution using water hyacinth: equilibrium, kinetics and thermodynamics study," Resource-Efficient Technologies, vol. 3, no. 1, pp. 71-77, 2017.

[13] M. Alshabanat, G. Alsenani, and R. Almufarij, "Removal of crystal violet dye from aqueous solutions onto date palm fiber by adsorption technique," Journal of Chemistry, vol. 2013, Article ID 210239, 6 pages, 2013.

[14] G. Alsenani, "Studies on adsorption of crystal violet dye from aqueous solution onto calligonum comosum leaf," Journal of American Science, vol. 9, no. 8, 2013.

[15] G. Alsenani, "Removal of Congo red dye from aqueous solution by date palm leaf base," American Journal of Applied Sciences, vol. 11, no. 9, pp. 1553-1557, 2014.

[16] E. U. Oyelude, J. A. M. Awudza, and S. K. Twumas, "Equilibrium, kinetic and thermodynamic study of adsorption of eosin yellow from aqueous solution using teak leaf litter powder," Scientific Reports, vol. 7, 2017.

[17] J. Idan, S. N. Jamil, L. C. Abdullah, and T. S. Choong, "Removal of reactive anionic dyes from binary solutions by adsorption onto quaternized kenaf core fiber," International Journal of Chemical Engineering, vol. 2017, Article ID 9792657, 13 pages, 2017.

[18] J. Idan, L. C. Abdullah, T. S. Choong, and S. N. Jamil, "Equilibrium, kinetics and thermodynamic adsorption studies of acid dyes on adsorbent developed from kenaf core fiber," Adsorption Science \& Technology, vol. 36, no. 1-2, pp. 694-712, 2017.

[19] https://mawdoo3.com/\%D9\%81\%D9\%88\%D8\%A7\%D8\% A6\%D8\%AF_\%D8\%B4\%D8\%AC\%D8\%B1\%D8\%A9_\%D8\% A7\%D9\%84\%D8\%B9\%D8\%B1\%D8\%B9\%D8\%B1.

[20] https://mawdoo3.com/\%D9\%81\%D9\%88\%D8\%A7\%D8\% A6\%D8\%AF_\%D8\%B9\%D8\%B4\%D8\%A8_\%D8\%A7\%D9\% 84\%D8\%AD\%D8\%B1\%D8\%AC\%D9\%84.

[21] G. M. Al-Senani and F. F. Al-Fawzan, "Adsorption study of heavy metal ions from aqueous solution by nanoparticle of wild herbs," The Egyptian Journal of Aquatic Research, vol. 44, no. 3, pp. 187-194, 2018.

[22] S. E. Agarry, C. N. Owabor, and A. O. Ajani, "Modified plantain peel as cellulose-based low-cost adsorbent for the adsorption of 2,6-dichlorophenol from aqueous solution: adsorption isotherms, kinetic modeling, and thermodynamic studies," Chemical Engineering Communications, vol. 200, no. 8, pp. 1121-1147, 2013.

[23] L. C. Urković, D. Ljubas, S. Šegota, and I. Bačić, "Photocatalytic degradation of lissamine green $\mathrm{B}$ dye by using nanostructured sol-gel $\mathrm{TiO}_{2}$ films," Journal of Alloys and Compounds, vol. 604, pp. 309-316, 2014.

[24] N. M. Mahmoodi, B. Hayati, and M. Arami, "Kinetic, equilibrium and thermodynamic studies of ternary system dye removal using a biopolymer," Industrial Crops and Products, vol. 35, no. 1, pp. 295-301, 2012.

[25] R. R. Mishra, P. Chandran, and S. S. Khan, "Equilibrium and kinetic studies on adsorptive removal of malachite green by the citrate-stabilized magnetite nanoparticles," RSC Advances, vol. 4, no. 93, pp. 51787-51793, 2014.

[26] N. Abdu-Salam and M. Buhari, "Adsorption of alizarin and fluorescein dyes onto palm seeds activated carbon: kinetic and thermodynamic studies," Journal of the Chemical Society of Pakistan, vol. 38, no. 4, 2016.

[27] R. Aziam, M. Chiban, E. Eddaoudi, A. Soudani, M. Zerbet, and F. Sinan, "Factors controlling the adsorption of acid blue 113 dye from aqueous solution by dried C. edulis plant as natural adsorbent," Arabian Journal of Geosciences, vol. 9, no. $659,2016$.

[28] R. Elmoubark, F. Z. Mahjoub, H. Tounsad et al., “Adsorption of textile dyes on raw and decanted Moroccan clays: kinetics, equilibrium and thermodynamics," Water Resources and Industry, vol. 9, pp. 16-29, 2015.

[29] A. M. Aljeboree, A. N. Alshirifi, and A. F. Alkaim, "Kinetics and equilibrium study for the adsorption of textile dyes on coconut shell activated carbon," Arabian Journal of Chemistry, vol. 10, pp. S3381-S3393, 2017.

[30] E. A. Moawed and M. F. El-Shahat, "Equilibrium, kinetic and thermodynamic studies of the removal of triphenyl methane dyes from wastewater using iodopolyurethane powder," Journal of Taibah University for Science, vol. 10, no. 1, pp. 46-55, 2016.

[31] E. O. Oyelude, J. A. M. Awudza, and S. K. Twumasi, "Equilibrium, kinetic and thermodynamic study of adsorption of eosin yellow from aqueous solution using teak leaf litter powder," Scientific Reports, vol. 7,12198 pages, 2017.

[32] L. R. Bonetto, F. Ferrarini, C. De Marco, J. S. Crespo, R. Guégan, and M. Giovanela, "Removal of methyl violet $2 \mathrm{~B}$ dye from aqueous solution using a magnetic composite as an adsorbent," Journal of Water Process Engineering, vol. 6, pp. 11-20, 2015.

[33] R. Saadi, Z. Saadi, R. Fazaeli, and N. E. Fard, "Monolayer and multilayer adsorption isotherm models for sorption from aqueous media," Korean Journal of Chemical Engineering, vol. 32, no. 5, pp. 787-799, 2015.

[34] Y. Miyah, A. Lahrichi, M. Idrissi, S. Boujraf, H. Taouda, and F. Zerrouq, "Assessment of adsorption kinetics for removal potential of crystal violet dye from aqueous solutions using Moroccan pyrophyllite," Journal of the Association of Arab Universities for Basic and Applied Sciences, vol. 23, no. 1, pp. 20-28, 2017.

[35] M. N. Rashed, M. A. El-Daim El Taher, and S. M. M. Fadlalla, "Adsorption of methylene blue using modified adsorbents from drinking water treatment sludge," Water Science and Technology, vol. 74, no. 8, pp. 1885-1898, 2016. 

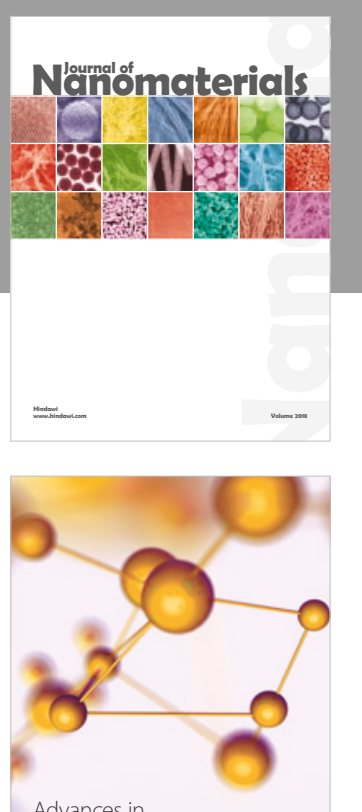

Physical Chemistry
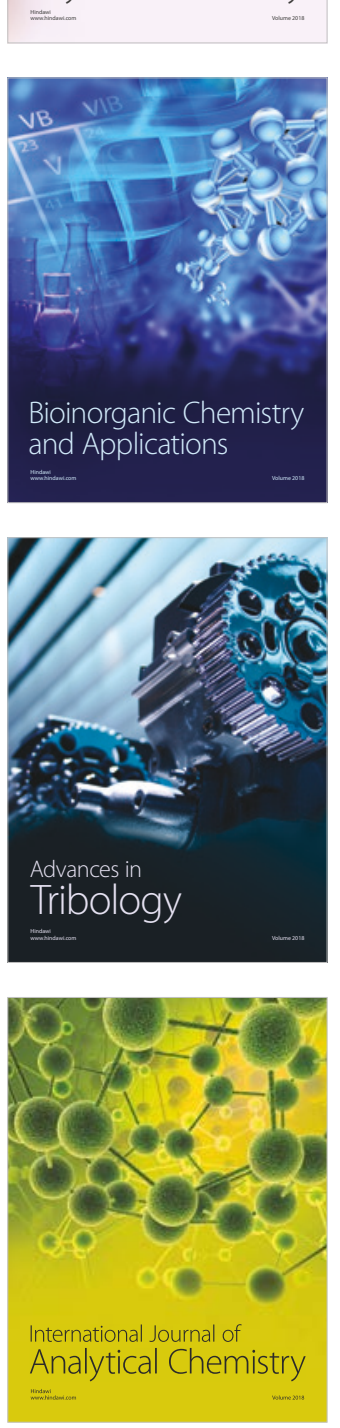

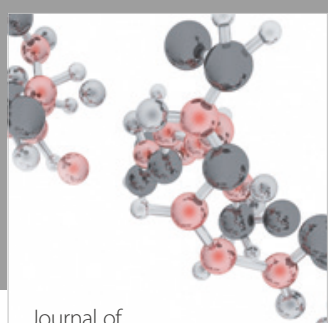

Analytical Methods

in Chemistry

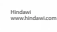

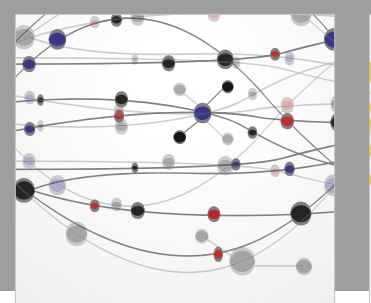

The Scientific World Journal

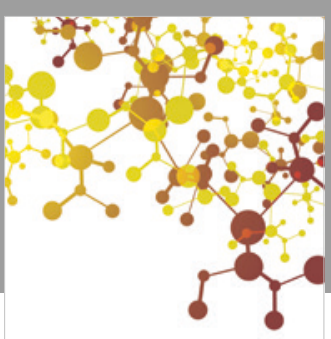

Journal of

Applied Chemistry
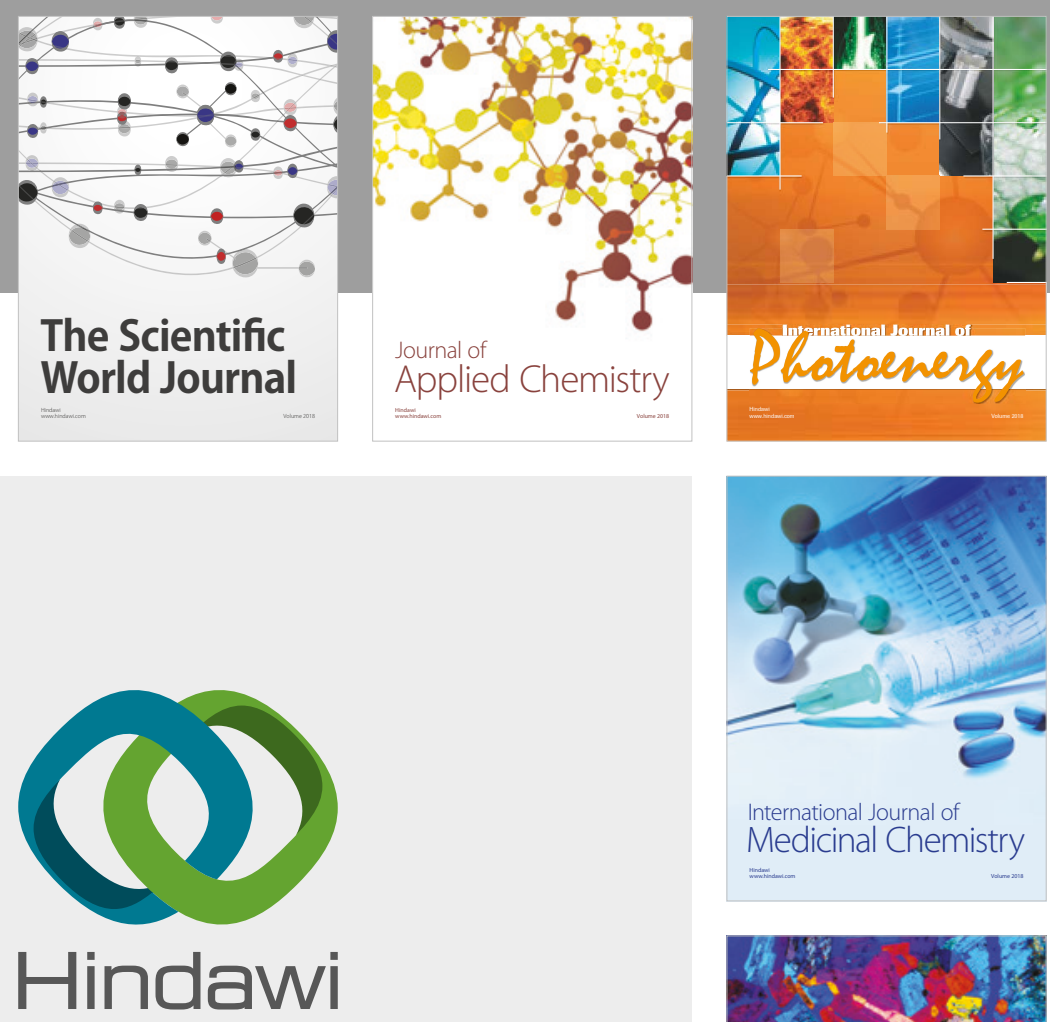

Submit your manuscripts at

www.hindawi.com
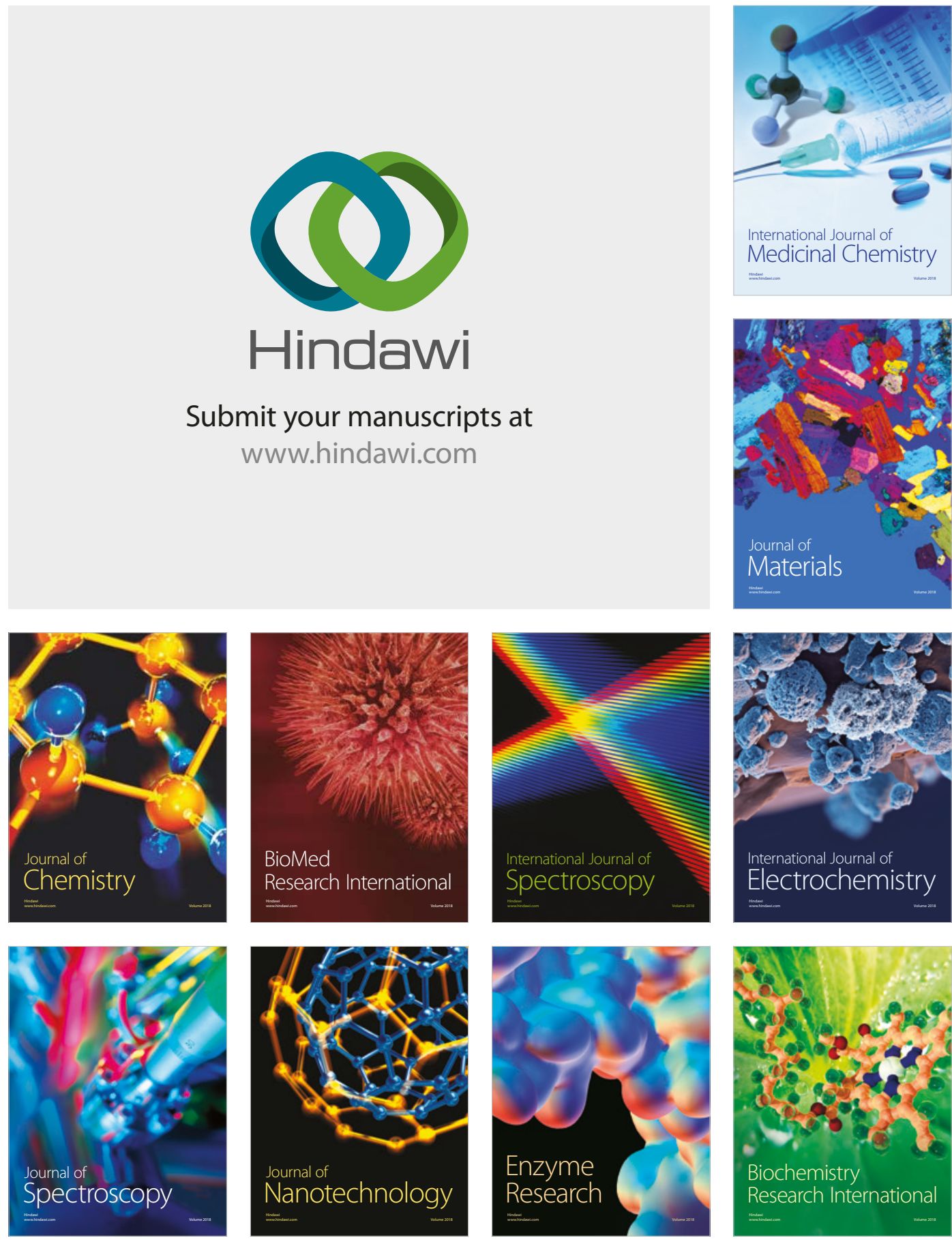
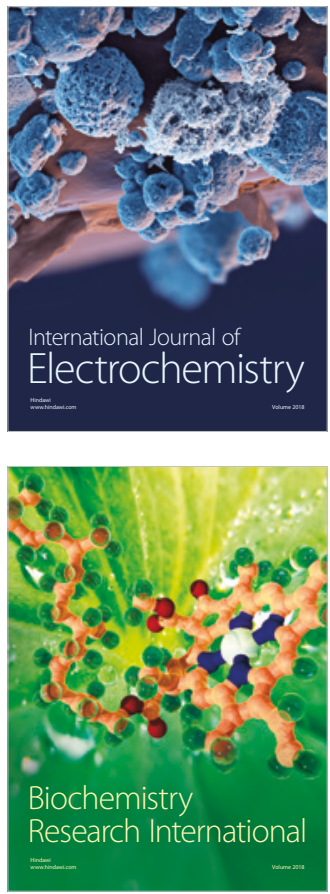